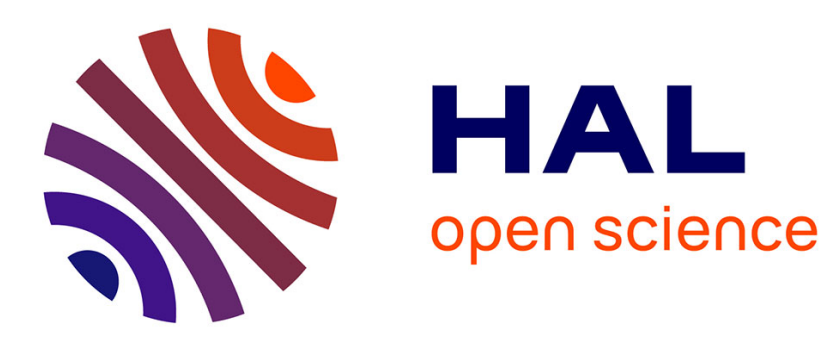

\title{
Height growth reconstruction of a boreal forest canopy over a period of 58 years using a combination of photogrammetric and lidar models
}

\author{
C. Vega, B. St-Onge
}

\section{- To cite this version:}

C. Vega, B. St-Onge. Height growth reconstruction of a boreal forest canopy over a period of 58 years using a combination of photogrammetric and lidar models. Remote Sensing of Environment, 2008, 112, p. 1784 - p. 1794 . 10.1016/j.rse.2007.09.002 . hal-00453861

\section{HAL Id: hal-00453861 \\ https://hal.science/hal-00453861}

Submitted on 5 Feb 2010

HAL is a multi-disciplinary open access archive for the deposit and dissemination of scientific research documents, whether they are published or not. The documents may come from teaching and research institutions in France or abroad, or from public or private research centers.
L'archive ouverte pluridisciplinaire HAL, est destinée au dépôt et à la diffusion de documents scientifiques de niveau recherche, publiés ou non, émanant des établissements d'enseignement et de recherche français ou étrangers, des laboratoires publics ou privés. 


\section{Height growth reconstruction of a boreal forest canopy over a period of 58 years using a combination of photogrammetric}

and lidar models

Running Title: Estimation of Canopy Height Growth Using Lidar and Photogrammetry

Cédric Véga ${ }^{1 \mathrm{a}}$, Benoît St-Onge ${ }^{2^{*}}$

${ }^{1}$ Institut des Sciences de 1'Environnement, Université du Québec à Montréal, Montreal, QC, Canada, H3C 3P8; Phone: 514-987-3000 \# 4982, Fax: 514-987-6784, Email: cedric.vega@teledetection.fr

${ }^{2}$ Benoît St-Onge, Département de Géographie, Université du Québec à Montréal, Montreal, QC, Canada, H3C 3P8; Phone: 514-987-3000 \# 0280, Fax: 514-987-6784, Email: st-onge.benoit@uqam.ca.

* Corresponding author.

Phone: 514-987-3000 \# 0280

Email: st-onge.benoit@,uqam.ca.

${ }^{a}$ Now with the UMR TETIS Cemagref-Cirad-Engref, Maison de la Télédétection en Languedoc-Roussillon, 500 rue J.F. Breton BP 5095, 34196 Montpellier Cedex 05, France. Tel.: (00 33) +4 67548719. 


\section{Abstract}

Field data describing the height growth of trees or stands over several decades are very scarce. Consequently, our capacity of analyzing forest dynamics over large areas and long periods of time is somewhat limited. This study proposes a new method for retrospectively reconstructing plotwise average dominant tree height based on a time series of high-resolution canopy height maps, termed canopy height models (CHMs). The absolute elevation of the canopy surface, or digital surface model (DSM), was first reconstructed by applying image-matching techniques to stereo-pairs of aerial photographs acquired in 1945, 1965, 1983, and 2003. The historical CHMs were then created by subtracting the bare earth elevation provided from a recent lidar survey from the DSMs. A method for estimating average dominant tree height from these historical CHMs was developed and calibrated for each photographic year. The accuracy of the resulting remote sensing height estimates was compared to age-height data reconstructed based on dendrometric measurements. The height bias of the remote sensing estimates relative to the verification data ranged from $0.52 \mathrm{~m}$ to $1.55 \mathrm{~m}$ ( $1.16 \mathrm{~m}$ on average). The corresponding root-mean-square errors varied between $1.49 \mathrm{~m}$ and $2.88 \mathrm{~m}(2.03 \mathrm{~m}$ average). Despite being slightly less accurate than historical field data, the quality of the remote sensing estimates is sufficient for many types of forest dynamics studies. The procedures for implementing this method, with the exception of the calibration phase, are entirely automated such that forest height growth curves can be reconstructed and mapped over large areas for which recent lidar data and historical photographs exist. 
Keywords: Forest canopy height; Growth; Lidar; Photogrammetry; Height growth;

Retrospective mapping 


\section{Introduction}

Changes in the height of forest canopies over time represent a key aspect of forest dynamics as they give indications of site quality, fluctuations in above-ground biomass, as well as the rate of gap opening and closure. Precise data on forest height dynamics are also required to run and verify dynamic models such as 3PG, CBM-CFS3, and TRIPLEX (Apps et al., 1999; Coops \& Waring, 2001; Zhou et al., 2005) to estimate annual allowable cuts based on predictions of future yields (Nelson, 2003; Peng, 2000; Vanclay, 2003). More recently, they were employed to understand the past and future fluctuations of forest carbon stocks. However, methods for acquiring high-resolution and accurate spatio-temporal data on forest heights over large areas are still lacking. Traditionally, tree height has been measured on permanent sample plots as part of forest inventory programs (Pothier \& Savard, 1998; Raulier et al., 2003). Age-height relationships were then developed using these data (e.g. Barnes et al., 1997; Clutter et al., 1983), reflecting the growth of individual trees that have remained dominant or co-dominant over their entire lifespan. However, long-term time series (i.e. over several decades) of such measurements are rare (Pothier \& Savard, 1998; Ung et al., 2001; Vanclay et al., 1995) and constitute a very sparse spatial sample of forest ecosystems. Forest inventory maps (Gillis \& Leckie, 1993) do provide spatially continuous data on height, and in many areas, short time series of these maps may be found. However, the height information they contain may not be suitable for scientific studies as it originatesfrom an error-prone photo-interpretation method that is generalized both spatially (stand averages) and quantitatively intomore or less imprecise height classes (Fournier et al., 2003). These 
limitations impede scientific progress on forest dynamics as well as our capacity to develop better policies for sustainable management and yield (Chen \& Popadiouk, 2002). New techniques for high-resolution stand height mapping have recently emerged. Airborne scanning laser altimetry, hereafter referred as "lidar" (for "Light Detection And Ranging”, see Lim et al. (2003) and Dubayah and Drake (2000) for reviews on lidar remote sensing of forests) and digital photogrammetry (Gagnon et al., 1993; Miller et al., 2000) are now considered to be among the most precise remote sensing means for mapping the height of forest canopies. Repeated acquisition of such data represents a promising solution for spatio-temporal growth estimates and the mapping of gap openings (Itaya et al., 2004; St- Onge \& Vepakomma, 2004; Yu et al., 2005). Lidar allows the acquisition of dense and accurate ground elevation and vegetation height data owing to the capacity of lidar pulses to penetrate even dense canopies. The precise geolocation of each emitted pulse is calculated based on the laser range, and the position and attitude of the sensor. The first returns represent the elevation of the first intercepted surface, i.e. the canopy surface in forest environments. Interpolating the first returns yields a digital surface model (DSM). The last returns can be classified into ground or non-ground categories using geometrical rules (Sithole \& Vosselman, 2004). Interpolating the ground-classified last returns provides a bare earth digital terrain model (DTM) with an altimetric accuracy of $30 \mathrm{~cm}$ or better (Ahokas et al., 2003; Hodgson \& Bresnahan, 2004; Hodgson et al., 2003; Reutebuch et al., 2003). Subtracting the DTM from the DSM yields a canopy height model (CHM), i.e. a high-resolution map of the forest canopy from which individual tree height or plotwise or stand-wise average height can be extracted (Næsset, 2002; Næsset et al., 2005; Persson et al., 2002). For any local 
neighbourhood, the average CHM height underestimates the corresponding average tree height becauseCHM points or pixels fall everywhere on the surface foliage, not just on tree apices that define tree height. Therefore, extracting single or average tree heights from lidar CHMs always requires a calibration phase to produce unbiased estimates. Various approaches have been proposed for recovering average tree height from lidar CHMs. In fine-scale studies, individual tree crowns are first delineated using image segmentation methods (Brandtberg et al., 2003; Hyyppä et al., 2001; Persson et al., 2002). The maximum lidar height within each crown is taken as an initial estimate of tree height and corrected for bias. Single tree heights are then averaged plotwise or standwise. For very dense lidar coverages, downward height biases of $1 \mathrm{~m}$ or less have been reported (Persson et al., 2002). However, methods requiring very high return densities are impractical for large areas. At a coarser scale, plot-level studies rely on statistical relationships between plot-wise lidar height distribution quantiles and field-measured mean plot height (e.g. Magnussen \& Boudewyn, 1998). Such methods were applied successfully for measuring the height of coniferous (Næsset et al., 2004) or deciduous stands (Lim et al., 2003) with sub-metre accuracies. Lidar is therefore generally recognized as the most accurate remote sensing means for estimating structural forest parameters (Lefsky et al., 2001). However, due to the recentness of airborne laser sensors, multitemporal lidar datasets enabling the study of forest dynamics are still rare (St-Onge \& Vepakomma, 2004; Yu et al., 2004). Lidar by itself therefore does not constitute an immediate solution for obtaining longterm retrospective time series of forest height maps. 
Historical aerial photographs have been employed to analyze and map forest dynamics retrospectively (Kadmon \& Harari-Kremer, 1999; Swetnam et al., 1999), and solutions for determining the orientation parameters of old photographs were proposed (e.g. Korpela, 2006). Most retrospective studies using aerial photographs concerned twodimensional attributes such as species composition (Rhemtulla et al., 2002). However, it has long been demonstrated that, with spatial intersection of the conjugate rays, individual tree height can be measured on stereopairswhen both the top and base of the trees are visible (Andrews, 1936; Spurr, 1960). According to the authors' experience, the photogrammetric quality of historical photographs has been high enough in Canada to allow accurate elevation measurements of surfaces since at least the middle of the 20th century. Because it has never been possible to measure the elevation of the tree bases when the ground is covered by dense forests, reliable photogrammetric height measurements are however only possible in open forests or for very flat lands. Solutions to this problem have occasionally been sought and applied to small areas on an experimental basis. Field topographic surveys (Fujita et al., 2003; Itaya et al., 2004), or derivations of the DTM from sparse photogrammetric measurements of ground elevations (Bar Massada et al., 2006; Næsset, 2002), among others, were used.

Combining stereo-photogrammetric measurements made from historical photographs with lidar DTM data offers a promising solution for measuring and mapping forest height retrospectively. For brevity, we shall henceforth refer to this approach as "photolidar". It consists of measuring the tree top elevation using the spatial intersection of the stereo rays and of subtracting the tree base elevation extracted from the lidar DTM at the tree location. A previous study demonstrated that the error of manual photo-lidar 
measurements, inwhich the tree top positionwas identified visually in the left and right photographs, does not exceed $1.51 \mathrm{~min} 90 \%$ of cases (St-Onge et al., 2004). However, the photogrammetric height measurements were done manually, excluding the use of this approach over large areas. The full automation of retrospective height mapping requires that the image correspondence problem central to stereo-matching be solved, i.e. that the conjugate points be identified. Using object- or surface-based methods, automated imagematching algorithms can establish correspondence by extracting conjugate points from a stereo-model (Barnard \& Fischler, 1982; Brown et al., 2003). The elevation of these is then calculated from their parallax (Hartley \& Sturm, 1997). Interpolating such automatically computed elevations yields a digital surface model (DSM) similar to those obtained from the first lidar returns. In forest environments, the photogrammetric DSM can be locally affected by matching errors caused by left-right image dissimilarities. The average error of automatically extracted elevations reported in previous studies lies between $0.5 \mathrm{~m}$ and $5.5 \mathrm{~m}$ (Miller et al., 2000; Næsset, 2002; St-Onge et al., in press), but can reach \pm 20 mlocally, particularly in shaded gaps (Halbritter, 2000). However, as we have recently shown, the plot-wise average height of dominant trees predicted that using the photo-lidar approach is highly correlated to estimates obtained with highly accurate lidar-only methods ( $\mathrm{r}$ up to $0.95 \mathrm{St-Onge}$ et al., in press). For even-aged canopies the photo-lidar CHM underestimated the lidar CHM by 0.49 min average. That study thus showed that even ifminute variations of the canopy height are notwell-represented in a photo-lidar CHM, the average plot height can be predicted with good accuracy. Our general goal was to introduce a new method for mapping forest height in the past over a relatively long term. Based on the well-demonstrated altimetric accuracy of lidar 
DTMs as well as the capacity of stereo-matching algorithms to map forest canopy surface elevations, we hypothesize that forest height changes can be reconstructed by applying the photo-lidar approach to time series of stereo aerial photographs and a single lidar DTM (assuming constant ground elevations several decades back). Therefore, the objectives of this study are to develop methods to 1) co-register multitemporal photogrammetric DSMs to a lidar DTM, 2) generate unbiased retrospective estimates of the average height of dominant trees at the plot level using the photo-lidar approach, and, 3) assess the error of the reconstructed height using independent retrospective field data.

\section{Study area and remote sensing data}

\subsection{Study area}

The $2 \mathrm{~km} 2$ study site falls within the managed part of the Training and Research Forest of Lake Duparquet (TRFLD), approximately $75 \mathrm{~km}$ north of Rouyn-Noranda, Quebec, Canada $\left(79^{\circ} 22^{\prime} \mathrm{W}, 48^{\circ} 30^{\prime} \mathrm{N}\right)$. This forest lies on the Canadian Shield and is characterized by soils dominated by argillaceous deposits of lacustrine origin (Brais \& Camiré, 1992). The undulating topography varies between 237 and $295 \mathrm{~m}$ and bears a vegetation characteristic of the balsam fir-paper birch (Abies balsamea [Mill.]-Betula papyrifera [Marsh.]) climate domain. The studied forest stands are mainly populated by jack pine (Pinus banksiana [Lamb.]), black spruce (Picea mariana [Mill.]), white spruce (Picea glauca L. [Moench]), paper birch (Betula papyrifera [Marsh.]), and trembling aspen (Populus tremuloides [Michx.]). The site burned in 1923 and the stands are mostly 
even-aged. The current dynamics are mostly driven by human activities initiated during the late 1970 s.

\subsection{Remote sensing data}

The dataset was composed of a lidar coverage and four sets of aerial photographs taken between 1945 and 2003. The lidar data (Table 1) was acquired by LaserMap Image Plus Inc. (Boisbriand, Canada) between August 14 and 16, 2003 with an Optech ALTM2050 sensor flown at $1000 \mathrm{~m}$ above-ground level. The $50,000 \mathrm{~Hz}$ sensor recorded the first and last return of each laser pulse. Lidar strips were acquired with a $15^{\circ}$ maximum scan angle and 50\% side overlaps. An automated strip-matching algorithm (TerraMatch, from Terrasolid Ltd., Helsinki) was applied to improve the geometric registration between adjacent swaths. The last returns were classified into ground and nonground categories using Terrasolid's Terrascan by the survey provider. The first returns ( 3 points $/ \mathrm{m} 2)$ and the ground-classified last returns $(0.19$ points $/ \mathrm{m} 2)$ were interpolated using a TIN model and then converted to a regular grid at $50 \mathrm{~cm}$ resolution to create a lidar DSM and DTM respectively.

Diapositives of 1945, 1965, 1983, and 2003 panchromatic aerial photographs were acquired. Three or four photographs were needed each year to cover the study area, resulting in two or three stereo-models per year. They were scanned at $16 \mu \mathrm{m}$ (1600 dpi) using an Epson Expression 1640XL scanner. The resulting digital images had a nominal ground pixel size varying between 19.1 and $25.1 \mathrm{~cm}$ respectively for the $1: 12,000$ and 1:15,840 photographic scales (Table 2). The overlap between images yielded a base- 
height ratio of 0.3 in 1945 and approximately 0.6 for the other years. The theoretical spatial intersection error based on the ground pixel size and the base to height ratio ranged from $40 \mathrm{~cm}(1983)$ to $56 \mathrm{~cm}$ (1945). The image quality varied greatly between each dataset, being best for the years 1965 and 1983. The stereo-pairs acquired in 2003 were taken in early spring when almost half of the deciduous trees were in leaf-off conditions. They were grainy and had rather poor contrasts. The 1945 images were of good quality but slightly blurry. The internal orientation parameters (focal length, coordinates of the principal point, and fiducial marks) were obtained from calibration reports except in the case of the 1945 photographs where only the nominal focal length could be recovered. For this set only, the coordinates of the fiducial marks were established using precise manual measurements made on the scanned diapositives. We assumed that no offset existed between the principal point and the fiducial centre.

\section{Methods}

\subsection{Collection of field data}

Individual tree height measurements of 134 dominant trees were made in the field in 2003 to calibrate manual photogrammetric measurements. The selected trees were marked on image printouts taken to the field to ensure that the same trees could afterward be measured photogrammetrically in the laboratory. They were selected to represent a very large range of heights for both conifers and deciduous (Table 3). Their height was measured using a Vertex III clinometer from Haglöf (Sweden). Two or more successive 
height measurements were made for each tree to avoid gross errors. Measurements were repeated until the difference between two successive measurements was $20 \mathrm{~cm}$ or less. The average of the two valid successive measurements was taken as the tree height. Twenty-three $400 \mathrm{~m} 2$ square plots located in jack pine stands were inventoried during the summer of 2005. The plots were selected in areas where no apparent or known disturbances had interrupted growth over the period 1945-2003. For each plot, three dominant trees corresponding to the three largest DBH were felled. A slice of wood was collected at a height of one metre and at heights corresponding approximately to each third of the remaining length, resulting in four slices per tree. The total height of each tree was measured with a distance tape immediately after felling. The position of the slices along the bole was established with a tape and converted to height. Each slice was sanded and the number of growth rings was counted to produce age-height pairs. This information was later used to reconstruct an age-height curve for each tree. Field plots were positioned along a topograpical gradient to capture various growth and site index conditions. Their geolocation was established using an SXBlue differential GPS (Geneq Inc., Montreal) with an accuracy of 2-3 m under canopy.

\subsection{Generation of the photo-lidar CHMs}

A photo-lidar canopy height model was generated for each of the four photographic coverages. For each year, automated stereo image matching was employed to generate a photogrammetric DSM (hereafter called "photo DSM") from which the lidar DTM elevations were subtracted to compute the photo-lidar CHM. The digital photogrammetric 
work was carried out using Virtuozo 3.5 from Supresoft Inc. (Bejing, China). This software performs a global image-matching technique based on relaxation (Büyüksalih \& Li, 2003). First, feature-based matching is done during the relative orientation process using a Förstner operator and a cross-correlation approach. The epipolar geometry is then computed and an area-based matching algorithm is run to identify a large number of conjugate points along a regular grid. These are interpolated to create a highresolution raster photo DSM.

The absolute orientation of the photogrammetric stereomodels was computed based on ground control points (GCPs) read from the lidar DSM and tied to conjugate points of the stereo-pairs. This method was designed to avoid the need for GCPs collected in the field as these are rarely available for old photographs. As a first approximation, features of the lidar DSM were manually associated to photographic positions based on a visual interpretation. Due to the difficulty of pinpointing lidar features, this procedure is expected to generate errors of a few metres. A special-purpose co-registration algorithm was developed to improve the automated selection of GCPs. After an initial photo DSM is computed based on the approximate GCPs, windows extracted from this photo DSM are then moved over the lidar DSM within a restricted search space and the correlation is calculated between the two DSM subsets for each window position. Locations with the highest correlation are taken as the exact photo DSM window position. There are then used to correct the initial absolute orientation, thus providing a precise value for the planimetric part of each GCP. The lidar Z is read at the centre of the repositioned photo DSM window and employed to adjust the control point vertically. Details of this procedure can be found in St-Onge et al. (2004) and St-Onge et al. (in press). In most 
cases, photo DSM windows were matched by correlating them to the corresponding lidar DSM subset, often in bare areas with topographical features. In some instances where GCPs were needed in areas devoid of bare patches, changes in the forest surface precluded the use of the above procedure. Therefore, some photo DSM windows were matched with other already precisely registered photo DSM (instead of lidar DSM). We proceeded backwards in time, registering the 2003 stereo-models first. The absolute orientation root-mean-square error (RMSE) was calculated with Virtuozo for the approximate and precise registrations respectively. In addition, orthophotos where generated based on the precisely registered stereo-models and corresponding DSMs. We checked that the planimetric fit between the orthophotos of different years was accurate by visually verifying that the geoposition of fixed, well-defined objects remained constant. This entire procedure was applied independently to each stereomodel. Checks were made to verify that there were no elevation discrepancies in the overlapping areas of adjacent DSMs of a given year. Finally, we compared elevation values of the photo DSMs with the corresponding lidar elevations at points located in bare areas to ensure that no vertical discrepancy existed between the precisely registered stereo-models and the lidar DSM. For this purpose, the elevation of 30 checkpoints was read on each photo DSM and lidar DSM. The small detected biases were removed by adding a constant value to all pixels of a given photo DSM. This corrected version of the photo DSMs was used to calculate the historical photo-lidar CHMs.

\subsection{Prediction of plot-wise mean dominant height}


Fig. 1 gives an overview of the entire procedure used to predict the plot-wise mean dominant height and to verify these predictions. This procedure is required mainly because photo-lidar or all-lidar CHMs do not represent the height of trees per se but rather an approximation of the continuous height variations of the canopy surface. However, they can be used to predict well-defined height attributes (mean tree height, Lorey's height, etc.) on a plot-wise or stand-wise basis (Means et al., 2000; Næsset, 2002). Because dominant tree height is a widely used variable, for example in site index estimates, and because dominant trees are visible on aerial photographs, we chose to estimate the plot-wise mean dominant tree height. We developed a prediction method that comprises two calibration stages (boxes 1 and 2 of Fig. 1) and verified its accuracy in a third, independent stage (box 3 of Fig. 1). The first stage consists of calibrating manual photo-lidar measurements with field data (St-Onge et al., 2004) so that these can be used retrospectively as unbiased, accurate estimates of individual tree height within chosen plots. This provides a solution to the absence of historical ground truth data. Biascorrected, manual photo-lidar measurements are then used in the second stage to create pseudo-reference data on mean plot-wise dominant height for 40 arbitrary plots per photographic year. This is achieved by measuring and averaging the height of three trees per pseudo-reference plot. Photo-lidar CHM metrics extracted from these plots are calibrated based on the pseudo-reference data and can then be used as estimates of mean plot-wise dominant height anywhere on the CHMs. These estimates were then independently verified (see Section 3.4).

In the following we provide further details about certain aspects of this two-stage method. In the first stage, manual photo-lidar measurements made on the 2003 photographs were 
compared to corresponding individual heights measured in the field in 2003. Preliminary tests showed that the measurement error was similar for both conifer $(n=89)$ and deciduous ( $\mathrm{n}=45)$ samples (Student $\mathrm{t}$-test: $\mathrm{p}=0.40)$. A single linear regression model was built to estimate field height from the manual photolidar measurements as follows:

$\hat{H}_{f}=b_{0}+b_{1} H_{m p}$

where $\hat{H}_{\mathrm{f}}$ represents field height, $\mathrm{H}_{\mathrm{mp}}$ the manual photo-lidar height, and $\mathrm{b}_{0}$ and $\mathrm{b} 1$ the regression coefficients. The aerial photographs of 1965 and 1983 had approximately the same scale and base-height ratio characteristics as those of 2003 (Table 2). Therefore, Eq. (1) was also used to correct the manual photo-lidar measurements for these three photographic datasets. However, the 1945 photographs possessed a much smallerbaseheight and a larger scale (Table 2) similar to the characteristics of the photographs used in St-Onge et al. (2004). We therefore chose to use their equation $(\mathrm{R} 2=0.95)$ to correct the manual photo-lidar measurements performed on the 1945 aerial photographs. To account for the remaining scale difference between their study (1:8000) and the scale of the 1945 photographs (i.e. the amount of additional downward bias caused by the smaller scale of the 1945 photographs compared to that of St-Onge et al., 2004), an additional correction factor based on the estimated bias from Spurr (1960) was applied.

In the second stage (Fig. 1, box 2), we calibrated the photolidar CHMs using 40 plots (20 respectively for conifers and deciduous) selected arbitrarily for each photographic year across different forest strata representative of the forest conditions in the study area. Three manual photo-lidar measurements of dominant trees were made for each plot. They 
were then corrected based on the equations developed in stage one and averaged plotwise. This value was used as the pseudo-reference for plot-wise mean dominant height $(\bar{H})$. Various photo-lidar CHM metrics (plotwise CHM mean maximum height at the 50th, 75th, 95th, and 99th percentiles) were extracted. The difference of each metric to the corresponding $\bar{H}$ values was computed to identify the best estimator for conifers and deciduous trees respectively. The metric yielding the lowest variance of the difference was selected. The average difference between the chosen metric and $\bar{H}$ was taken as the expected bias (b) of this photo-lidar CHM metric. A value of b was calculated separately for each photographic year and forest type (i.e. deciduous and coniferous). The following equation was used to estimate the plot-wise mean dominant height $(\hat{H})$ at any location of a photo-lidar CHM once the bias values were obtained:

$\hat{H}=\mathrm{CHM}_{\mathrm{m}}+\mathrm{bi}$

where $\mathrm{CHM}_{\mathrm{m}}$ is the chosen photo-lidar plot height metric for a given photographic year and forest type, and bi is the corresponding bias value. Note that for the 2003 photographs, deciduous plotswhere not considered because more than half of the stands where still in leaf-off conditions, a situation that led to poor image-matching results and unreliable photo-lidar CHM values.

\subsection{Verification of retrospective height estimates}


In stage three (Fig. 1, box 3), values of $\hat{H}$ were compared to the "true" average heights derived from verified age-height curves. First, the site index (SI) was calculated for each tree based on the age at $1 \mathrm{~m}$ and the total height for the three felled trees using the following Pothier and Savard (1998) equation:

$S I=b_{1}+H_{d}^{b_{2}}\left(1-e^{-b_{3} A_{c}}\right)^{b_{4} H_{d}{ }^{-b_{5}}}$

where SI represents the site index,Hd is the dominant height, Ac is the age corrected at 1 m, and b1 to b5 are specific values (see Table 6) published by Pothier and Savard (1998). Based on this SI value, the following model was employed to predict the height at the years corresponding to the slice and photographic years (Pothier \& Savard, 1998, coefficient values appear in Table 6):

$H_{d}=b_{1}+b_{2} S I^{b_{3}}\left(1-e^{-b_{4} A_{c}}\right)^{b_{5} S I^{-b_{6}}}$

The height predictions for the slice years (Hd) were compared to the actual height of the slices measured in situ to ensure that Eq. (4) could be used reliably to verify the photolidar predictions. This verification was made by computing the overall average difference (bias) and RMSE between the slice heights and the corresponding Hd values. After checking the accuracy of theseHd values, the average SI for each plot was input into Eq. (4) to estimate the height of dominant trees at photographic years for all verification plots. Because of their accuracy, these estimates were considered as reference data and used to check the photo-lidar height values. To do so, the bias and RMS error of $\hat{H}$ values 
(Eq. (2)) was assessed by comparing them to the corresponding plot-wise Hd values. This comparison was made for conifer trees only, as slices could not be extracted from deciduous tree stems to reconstruct retrospective height growth reliably.

\section{Results}

\subsection{Generation of the photo-lidar CHMs}

Photo-lidar CHMs and orthophotos were generated for the years 1945, 1965, 1983, and 2003 (Fig. 2). The RMSE of the GCPs selected visually for a first approximation of the absolute orientation of the stereo-models was generally around $2 \mathrm{~m}$. After correction using the automated co-registration method, the registration RMS errors dropped to values between $0.25 \mathrm{~m}$ and $0.78 \mathrm{~min}$ planimetry, and between 0.27 mand $1.01 \mathrm{~min}$ altimetry (Table 4). The worst fits were observed for the two oldest stereomodels. Small discrepancies were found for each photographic year between the lidar and the photo DSM in bare areas. The vertical bias e of 30 sample bare ground points ranged from 0.03 $\mathrm{m}$ for the 2003 stereo-model, to $-0.35 \mathrm{~m}$ for that of 1965 (Table 4). The standard deviations calculated on the same points varied between $0.37 \mathrm{~m}$ and $0.94 \mathrm{~m}$. Corrections for biases were made before canopy height measurements were performed.

\subsection{Height calibration}


For the 134 trees measured, the manual photo-lidar measurements made on the 2003 aerial photographs underestimated field height by $0.49 \mathrm{~m}$ on average. The mean absolute error was $0.98 \mathrm{~m}$, and the minimum and maximum absolute values were respectively 0.03 and $2.96 \mathrm{~m}$. The regression model linking field and photo-lidar measurements yielded an $\mathrm{R} 2$ of 0.96 with a standard error of estimate of $1.09 \mathrm{~m}$ (Eq. (5)). Eq. (5) was used to predict field height from the manual photo-lidar measurements for the three most recent photographic years, while Eq. (6) was used for 1945.

$\hat{H}_{t}=0.83+0.98 H_{M P L M}$

$\hat{H}_{t}=1.72+0.98 H_{M P L M}$

Table 5 shows the difference between the average of three corrected manual photo-lidar per-plot measurements and the value of the chosen photo-lidar metrics for the 40 arbitrary plots for each photographic year. The selected photo-lidar metric varied between forest type and year. The differences (bias) ranged from $2.35 \mathrm{~m}$ to $4.0 \mathrm{~m}$, and RMSEs from 1.30 to $3.68 \mathrm{~m}$. These bias values were then used to correct the corresponding metric values of the 23 plots used for independent verification. For this purpose, the plot-wise average dominant height estimated using the above corrected photo-lidar metrics was compared to the "true" height reconstructed from the slices taken from the felled trees for the 23 verification plots. The age-height curves were established based on the site index values and Eqs. (3) and (4) from Pothier and Savard (1998) with the coefficients presented in Table 6. Comparing the height values derived from Eq. (4) to those estimated from the 
slices, we found that the former underestimated the latter reference heights by $0.41 \mathrm{~m}$ on average (with a standard deviation of $1.47 \mathrm{~m}$, see Table 7). This level of error was

deemed acceptable, and the height at photographic years was computed with Eq. (4). The resulting plot-wise dominant height values were then compared to the prediction of average dominant height obtained from the corrected photo-lidar metrics (Table 8). Results show that the dominant height was always underestimated by the corrected photo-lidar metric to some degree. The largest average downward bias, $1.55 \mathrm{~m}$, was observed in the 1945 data, while the 1983 photo-lidar CHMs yielded the smallest one at $0.52 \mathrm{~m}$. The RMSE did not exceed $2.88 \mathrm{~m}$.

\section{Discussion}

This paper presents, to the best of our knowledge, the first attempt to measure forest canopy height retrospectively and to reconstruct the changes in average dominant tree height per plot using photo-lidar canopy height models. A small bias affected the photolidar measurements $(0.52$ to $1.55 \mathrm{~m})$ and the RMSE was also low (1.49 to $2.88 \mathrm{~m})$, i.e. significantly lower than the typical height class intervals of forest inventory maps. A number of factors may have caused these small discrepancies. Although the windowbased co-registration method implemented in this study allowed to produce sub-metric XYZ accuracy for all photographic years (see Table 4), analyzing the RMS errors revealed a higher altimetric registration uncertainty in 1945 and 1965. Due to the quasiabsence of canopy gaps during that period, reliable points were only found in open areas located on hill slopes of the northern part of the stereo-models, leading to less stability of 
the models. In 1983 and 2003, however, roads and clear cuts allowed a better distribution of ground control points and greater registration accuracy. To increase the possibilities of finding good control points in densely forested areas, we plan to use aerotriangulation methods applied to blocks of photographs. This approach increases coverage, thus augmenting the probability of finding good control points and improving the error analysis of the models (Kasser \& Egels, 2001; Krauss \& Waldhäusl, 1998). The use of manual photo-lidar measurements to correct the photo-lidar CHMs may also explain part of the error. The measurements were particularly difficult in 1945 due to a lower resolution (the photographs were slightly blurred compared to more recent ones) and a small average tree height (most trees were 6 to $8 \mathrm{~m}$ high). Pinpointing the apex of the trees in these conditions was subject to greater uncertainty. This is supported by the results of St-Onge et al. (2004) that showed that the clarity of the tree crowns on the photographs has a significant impact on the height error. We also suspect that the downward bias of the manual photo-lidar measurements on the 1945 photographs was higher than the values obtained for the other years due to the lesser quality of this dataset. The stereo-matching process tends to lead to uncertainty of the overall results. In conifer stands for example, elongated crown shapes, gaps, and a higher vertical variability create matching difficulties that usually result in the underestimation of the canopy surface height (Korpela \& Anttila, 2004). A few local blunders caused by a complex canopy surface (Halbritter, 2000) may also have affected the overall statistics by influencing the calibration of the photo-lidar CHMs. Matching quality was best for even-aged and dense deciduous stands and lower for heterogeneous conifers stands (Næsset, 2002). Preliminary statistical tests made early in this study (results not shown) had indicated 
matching quality differences between years that could be explained by the changing canopy height and structure.

Finally, part of the RMSE of the retrospective height estimates might be due to the sampling procedure. Since only three trees were sampled per plot (for calibration or validation), and because the photogrammetrically measured trees did not necessarily correspond to those that were felled to extract slices, discrepancies between these two samples for the same plot might arise. There are also no means of ensuring that the felled trees were in dominant position over the entire time period covered by this study. Representativeness tends to be a more acute problem for plots located on very poor sites. The height and density of these plots was low and variable, increasing the risk of sampling nonrepresentative trees in addition to creating more difficult matching conditions. What is more, the reference heights at the time the photographs were taken contain some uncertainty as revealed by comparing Eq. (4) estimates to the height of slices.

In summary, the errors reported in Table 8 most likely result from a combination of coregistration, manual measurement calibration, and stereo-matching errors, as well as sampling and averaging artefacts. Nevertheless, the overall error appears sufficiently low to allow a relatively accurate retrospective reconstruction of dominant tree height at a fairly high resolution (here $20 \mathrm{~m} \times 20 \mathrm{~m}$ ). To the best of our knowledge, combining existing lidar and photographic datasets is currently the only way to produce historical maps of tree height to analyze forest dynamics over several decades. Time series of the CHMs can reveal the spatially-explicit evolution of tree height and the occurrence of small or large gaps created by disturbances such as tree falls, fires, windthrow or 
harvesting. The potential for improving our understanding of forest dynamics using this means appears to be high. Care will however have to be taken to carefully calibrate all models and to verify that the ground topography did not change significantly due to factors such as erosion, fluvial dynamics, or peat accumulation. Where change is suspected, manual photogrammetric measurements of ground elevation can be performed to check the stability of ground elevation over time if the targeted areas are bare or covered by sparse vegetation. Finally, recent advances in matching algorithms specific to forested conditions (Baltsavias et al., 2006; Lai, 2000; Sheng et al., 2001, 2003) suggest that improvements in the photo-lidar CHMs can be expected and that the overall accuracy of the proposed method could improve proportionally.

\section{Conclusions}

This study's objectives were to reconstruct the average height of dominant trees retrospectively at the scale of $400 \mathrm{~m}^{2}$ plots by combining a DTM and historical stereomodels of aerial photographs. The independent verification of results lead to the conclusion that, at least in the case of even-aged coniferous trees (jack pine), the dominant height can be recovered with a bias not exceeding $1.55 \mathrm{~m}$ and a RMSE below $2.88 \mathrm{~m}$, under the conditions of this study. The method required that manual photogrammetric measurements of tree height used as pseudo-reference data be calibrated using in-situ data. However, it can be assumed that this procedure will no longer be necessary once measurements biases are known for various photo scales and base-to-height ratios. Therefore, it would be possible to apply this method without the 
need for field information, unless verification is sought as well. Using aerotriangulation techniques, large blocks of photographs could be registered to lidar DTMs to create historical photo-lidar CHMs over large areas. By dividing a territory in $20 \mathrm{~m} \times 20 \mathrm{~m}$ cells for example, retrospective maps of dominant height could be produced. As the lidar coverage is rapidly increasing, and because historical aerial photographs can be found over many regions, the historical reconstruction of forest dynamics will become feasible in many areas. In addition, ongoing efforts to improve stereo-matching algorithms specific to the complex structure of forest canopies will likely lead to an increase in the accuracy of photo-lidar reconstruction.

The photo-lidar method needs to be verified on other sites that have different topographical and forest conditions. In particular, the success of stereo-matching in more difficult environments such as uneven-aged or open forests needs to be carefully evaluated. Moreover, the ability to detect the opening and closing of smaller gaps will have to be verified. However, the possibility exists of using the historical photo-lidar CHMs to map other important forest attributes, such as biomass, in order to better understand the dynamics of carbon sequestration in forest environments. In the long term, the proposed method may also serve to study the effect of climate change on the forest over long time intervals starting in the mid 20th century.

\section{References}

Ahokas, E., Kaartinen, H., \& Hyyppa, J. (2003). A quality assessment of airborne laser scanner data (pp.1-7). In H.-G. Mass et al. (Eds), Proc. of the ISPRS workshop on 3-D 
reconstruction from airborne laser scanner and InSAR data. Dresden: Institute of Photogrammetry and Remote Sensing.

Andrews, G. S. (1936). Tree-heights from air photographs by simple parallax measurements. The Forestry Chronicle, 12, 152-197.

Apps, M. J., Kurz, W. A., Beukema, S. J., \& Bhatti, J. S. (1999). Carbon budget of the Canadian forest product sector. Environmental Science \& Policy, 2(1), 25-41.

Baltsavias, E. P., Gruen, A., Küchler, M., Thee, P., Waser, L. T., \& Zhang.L. (2006). Tree height measurements and tree growth estimation in a mire environment using digital surface models. In workshop on 3D remote sensing in forestry. Vienna: Institute of Surveying, Remote Sensing and Land Information.

Bar Massada, A., Carmel, Y., Even Tzur, G., Grünzweig, J. M., \& Yakir, D. (2006). Assessment of temporal changes in aboveground forest tree biomass using aerial photographs and allometric equations. Canadian Journal of Forest Research, 36(10): $2585-2594$.

Barnard, S.T., \& Fischler, M.A. (1982).Computational stereo. Computing Surveys, 14(4), $553-572$.

Barnes, B. V., Zak, D. R., Denton, S. R., \& Spurr, S. H. (1997). Forest ecology (pp. 792). (4th Edition) New York: Wiley.

Brais, S., \& Camiré, C. (1992). Keys to soil moisture regime evaluation for northwestern Quebec. Canadian Journal of Forest Research, 22, 718-724. 
Brandtberg, T., Warner, T. A., Landenberger, R. E., \& McGraw, J. B. (2003). Detection and analysis of individual leaf-off tree crowns in small footprint, high sampling density lidar data from the eastern deciduous forest in North America. Remote Sensing of Environment, 85, 290-303.

Brown, M. Z., Burschka, D., \& Hager, G. D. (2003). Advances in computational stereo. IEEE Transactions on Pattern Analysis and Machine Intelligence, 25(8), 993-1008.

Büyüksalih G., \& Z. Li. (2003). Practical experiences with automatic aerial triangulation using different software packages. Photogrammetric Record, 18(102), 131-155.

Chen, H. Y. H., \& Popadiouk, R. V. (2002). Dynamics of north amarican boreal mixedwoods. Environmental Reviews, 10, 137-166.

Clutter, J. L., Fortson, J. C., Pienaar, L. V., Brister, G. H., \& Bailey, R. L. (1983). Timber management: a quantitative approach (pp. 333). New York: Wiley.

Coops, N., \& Waring R. H. (2001). The use of multiscale remote sensing imagery to derive regional estimates of forest growth capacity using 3-PGS. Remote Sensing of Environment, 75, 324-334.

Dubayah, R. O., \& Drake, J. B. (2000). Lidar Remote Sensing for Forestry. Journal of Forestry, 98(6), 44-46.

Fournier, R. A., Luther, J. E., Guindon, L., Lambert, M. - C., Piercey, R. J., Hall, R. J., \& Wulder, M. A. (2003). Mapping aboveground tree biomass at the stand level from 
inventory information: test cases in Newfoundland and Quebec. Canadian Journal of Forest Research, 33, 1846-1863.

Fujita, T., Itaya, A., Miura, M., Manabe, T., \& Yamamoto, S.- I. (2003a). Long-term canopy dynamics analysed by aerial photographs in a temperate old-growth evergreen broad-leaved forest. Journal of Ecology, 91, 686-693.

Gagnon, P. A., Agnard, J. P., \& Nolette, C. (1993). Evaluation of a softcopy photogrammetry system for tree-plot measurement. Canadian Journal of Forest Research, 23, 1781-1785.

Gillis, M. D., \& Leckie, D. G. (1993). Forest inventory mapping procedures across Canada. For. Can. Petawawa Natl. For. Inst. Inf. Rep. PI-X-114.

Halbritter, K. (2000). Remote sensing for quantifying structural diversity in forests for forest biodiversity assessment. The research program BEAR: Indicators for Monitoring and Evaluation of Forest Biodiversity in Europe, Tech. Rep. No. 6, 10 p. (http://www.algonet.se/ bear, February 12, 2007).

Hartley, R. I. (1997). Triangulation. Computer Vision and Image Understanding, 68(2), $146-157$.

Hodgson, M. E., \& Bresnahan, P. (2004). Accuracy of airborne lidar-derived elevation: empirical assessment and error budget. Photogrammetric Engineering \& Remote Sensing, 70(3), 331-339. 
Hodgson, M. E., Jensen, J. R., Schmidt, L., Schill, S., \& Davis, B. (2003). An evaluation of lidar- and IFSAR- derived digital elevation models in leaf-on conditions with USGS level 1 and level 2 DEMs. Remote Sensing of Environment, 84, 295-308

Hyyppä, J., Kelle, O., Lehikoinen, M., \& Inkinen, M. (2001). A segmentation-based method to retrieve stem volume estimates from 3-D tree height models produced by laser scanners. Transactions on Geoscience and Remote Sensing, 39(5), 969-975.

Itaya, A., Miura, M., \& Yamamoto, S.- I. (2004). Canopy height changes of an oldgrowth evergreen broad-leaved forest analyzed with digital elevation models. Forest Ecology and Management, 19, 403-411.

Kadmon, R., \& Harari-Kremer, R. (1999). Studying Long-Term Vegetation Dynamics Using Digital Processing of Historical Aerial Photographs. Remote Sensing of Environment, 68(2), 164-176.

Kasser, M., \& Egels, Y. (2001). Photogrammétrie numérique (p. 378). Paris: Lavoisier.

Korpela, I. (2006). Geometrically accurate time series of archived aerial images and airborne lidar data in a forest environment. Silva Fennica, 60(1), 109-126.

Korpela, I., \& Anttila, P. (2004). Appraisal of the mean height of trees by means of image matching of digitalsed aerial photographs. Photogrammetric Journal of Finland, 19(1), 23-36.

Krauss, K., \& Waldhäusl, P. (1998). Manuel de photogrammetry, principes et procédés fondamentaux (p. 407). Paris: Hermes. 
Lai, S.- H. (2000). Robust image matching under partial occlusion and spatially varying illumination change. Computer Vision and Image Understanding, 78, 84-98.

Lefsky, M. A., Cohen, W. B., \& Spies, T. A. (2001). An evaluation of alternate remote sensing products for forest inventory, monitoring, and mapping of Douglas-fir forests in western Oregon. Canadian Journal of Forest Research, 31, 78-87.

Lim, K., Treitz, P., Baldwin, K., Morrison, I., \& Green, J. (2003). Lidar remote sensing of biophysical properties of tolerant northern hardwood forests. Canadian Journal of Remote Sensing, 29(5), 658-678.

Magnussen, S., \& Boudewyn, P. (1998). Derivations of stand heights from airborne laser scanner data with canopy-based quantile estimators. Canadian Journal of Forest Research, 28(7), 1016-1031.

Means, J. E., Acker, S. E., Fitt, B. J., Renslow, M., Emerson, L., \& Hendrix, C. J. (2000). Predicting forest stand characteristics with airborne scanning lidar. Photogrammetric Engineering \& Remote Sensing, 66(11), 1367-1371.

Miller, D. R., Quine, C. P., \& Hadley, W. (2000). An investigation of the potential of digital photogrammetry to provide measurements of forest characteristics and abiotic damage. Forest Ecology and Management, 135, 279-288.

Næsset, E. (2002). Predicting forest stand characteristics with airborne scanning laser using a practical two-stage procedure and field data. Remote Sensing of Environment, 80, 88-99. 
Næsset, E., Bollandsas, O. M., \& Gobakken, T. (2005). Comparing regression methods in estimation of biophysical properties of forest stands from two different inventories using laser scanner data. Remote Sensing of Environment, 94(4), 541-553.

Næsset, E., Gobakken, T., Holmgren, J., Hyyppä, H., Hyyppä, J., Maltano, M., Nilsson, M., Olsson, H., Persson, Å., \& Söderman, U. (2004). Laser scanning of forest resources: the nordic experience. Scandinavian Journal of Forest Research, 19, 482499.

Nelson, J. (2003). Forest-level models and challenges for their successful application. Canadian Journal of Forest Research, 33, 422-429.

Peng, C. (2000). Understanding the role of forest simulation models in sustainable forest management. Environmental Impact Assessment Review, 20(4), 481-501.

Persson, A., Holmgren, J., \& Söderman, U. (2002). Detecting and measuring individual trees using an airborne laser scanner. Photogrammetric Engineering \& Remote Sensing, 68(9), 925-932.

Pothier, D., \& Savard, F. (1998). Actualisation des tables de production pour les principales espèces forestières du Québec (p. 183). Québec: Ministère des Ressources Naturelles du Québec.

Raulier, F., Lambert, M.- C., Pothier, D., \& Ung, C.- H. (2003) Impact of dominant tree dynamics on site index curves. Forest Ecology and Management, 184(1-3), 65-78. 
Reutebuch, S. E., McGaughey, R. J., Andersen, H. E., \& Carson, W. W. (2003). Accuracy of a high-resolution lidar terrain model under a conifer forest canopy. Canadian Journal of Remote Sensing, 29(5), 527-535.

Rhemtulla, J. J., Hall, D. J., Higgs, E. S., \& Macdonald, E. S. (2002). Eighty years of change: vegetation in the montane ecoregion of Jasper National Park, Alberta, Canada. Canadian Journal of Forest Research, 32, 2010-2021.

Sheng, Y., Gong, P., \& Biging, G. S. (2003). Model-based conifer canopy surface reconstruction from photographic imagery: overcoming the occlusion, foreshortening, and edge effects. Photogrammetric Engineering and Remote Sensing, 69(3), 249-258.

Sheng, Y., Gong, P., \& Biging, G. S. (2001). Model-based conifer-crown surface reconstruction from high-resolution aerial images. Photogrammetric Engineering and Remote Sensing, 67(8), 957-965.

Sithole, G., Vosselman, G. (2004). Experimental comparison of filter algorithms for bareearth extraction from airborne laser scanning point clouds. ISPRS Journal of Photogrammetry and Remote Sensing, 59(1-2), 85-101.

Spurr, S. H. (1960). Photogrammetry and photo-interpretation (p. 472). New York: The Ronald Press Company.

St-Onge, B., Jumelet, J., Cobello, M., \& Véga, C. (2004). Measuring individual tree height using a combinaison of stereophotogrammetry and lidar. Canadian Journal of Forest Research, 34, 2122-2130. 
St-Onge, B., Véga, C., Fournier, R. A., \& Hu, Y. (in press). Mapping canopy height using a combination of digital photogrammetry and airborne scanning laser altimetry. International Journal of Remote Sensing.

St-Onge, B., \& Vepakomma, U. (2004). Assessing forest gap dynamics and growth using multitemporal laser-scanner data (pp.173-178). In M. Thies et al. (Eds.), Proc. of the ISPRS Workshop on laser-scanners for forest and landscape assessment (pp. 173178). Fribourg: Institute for Forest Growth.

Swetnam, T. W., Allen, C. D., \& Betancourt, J. L. (1999). Applied historical ecology: using the past to manage for the future. Ecological applications, 9, 1189-1206.

Ung, C. H., Bernier, P. Y., Raulier, F., \& Fournier, R. A. (2001). Biophysical site indices for shade tolerant and intolerant boreal species. Forest Science, 47(1), 83-95.

Vanclay, J. K. (2003). Realizing opportunities in forest growth modeling. Canadian Journal of Forest Research, 33, 536-541.

Vanclay, J. K., Skovsgaard, J. P. \& Pilegaard Hansen, C. (1995). Assessing the Quality of Permanent Sample Plot Databases for Growth Modelling in Forest Plantations. Forest Ecology and Management, 71, 177- 186.

Yu X. , Hyyppä, J., Kaartinen, H., Hyyppä, H.,Maltamo, M., \& Rönnholm, P. (2005). Measuring The Growth of Individual Trees Using Multitemporal Airborne Laser Scanning Point Clouds. ISPRS WG III/3, III/4, V/3 Workshop "Laser scanning 2005", Enschede, the Netherlands, September 12-14, (pp. 5). 
Yu, X., Hyyppä, J., Kaartinen, H., \& Maltano, M. (2004). Automatic detection of harvested trees and determination of forest growth using airborne laser scanning. Remote Sensing Environment, 90, 451-462.

Zhou, X., Peng, C., Dang, Q.-L., Chan, J., \& Parton, S. (2005). Predicting forest growth and yield in northeastern Ontario using the process-based model of triplex 1.0. Canadian Journal of Forest Research, 35, 2268-2280. 


\section{Figure legends}

Fig. 1. Summary of the processing steps.

Fig. 2. PCHMs for the four stereo-models with the corresponding orthoimages (note that the 2003 PCHM was computed in partly leaf-off conditions). 

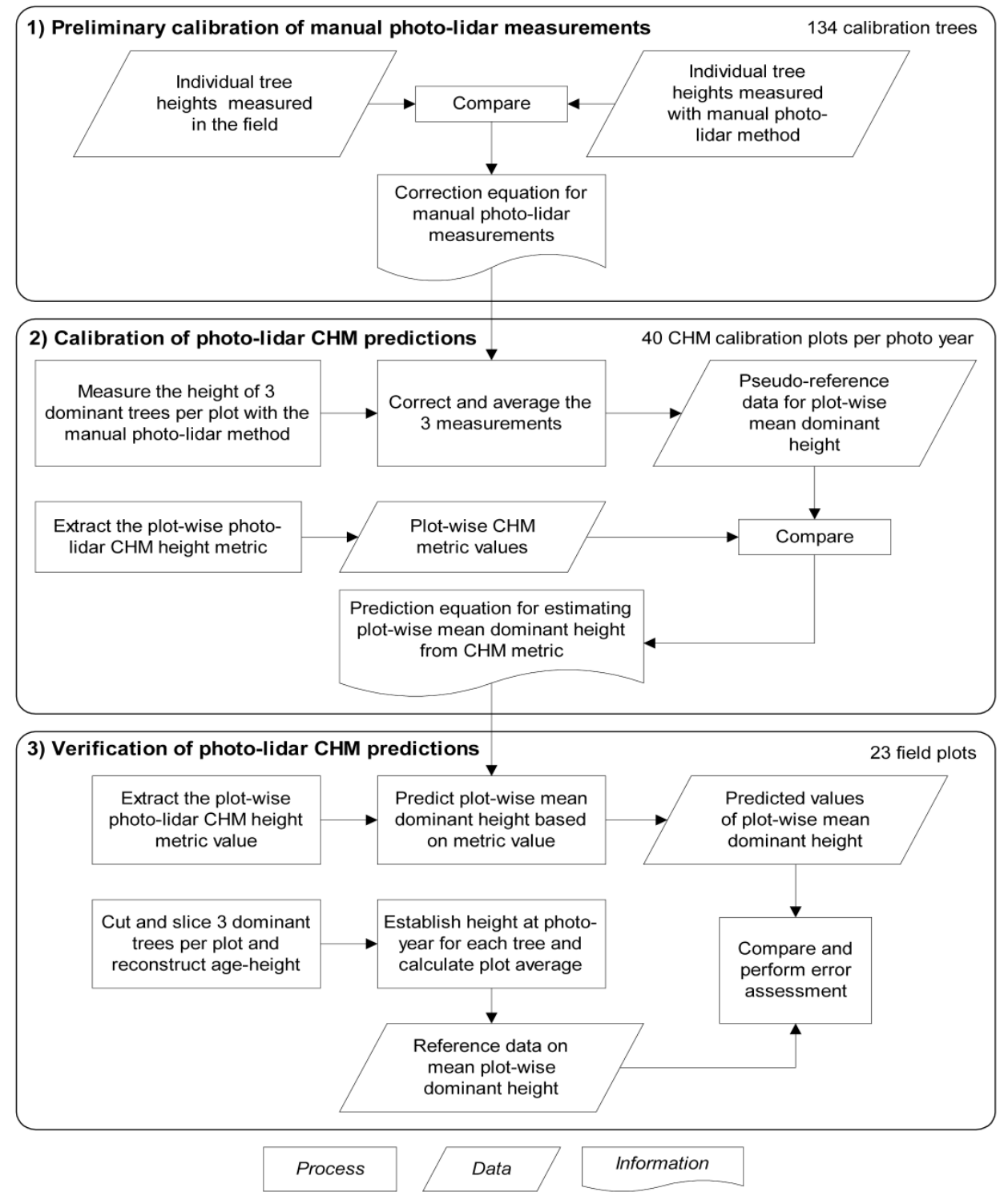

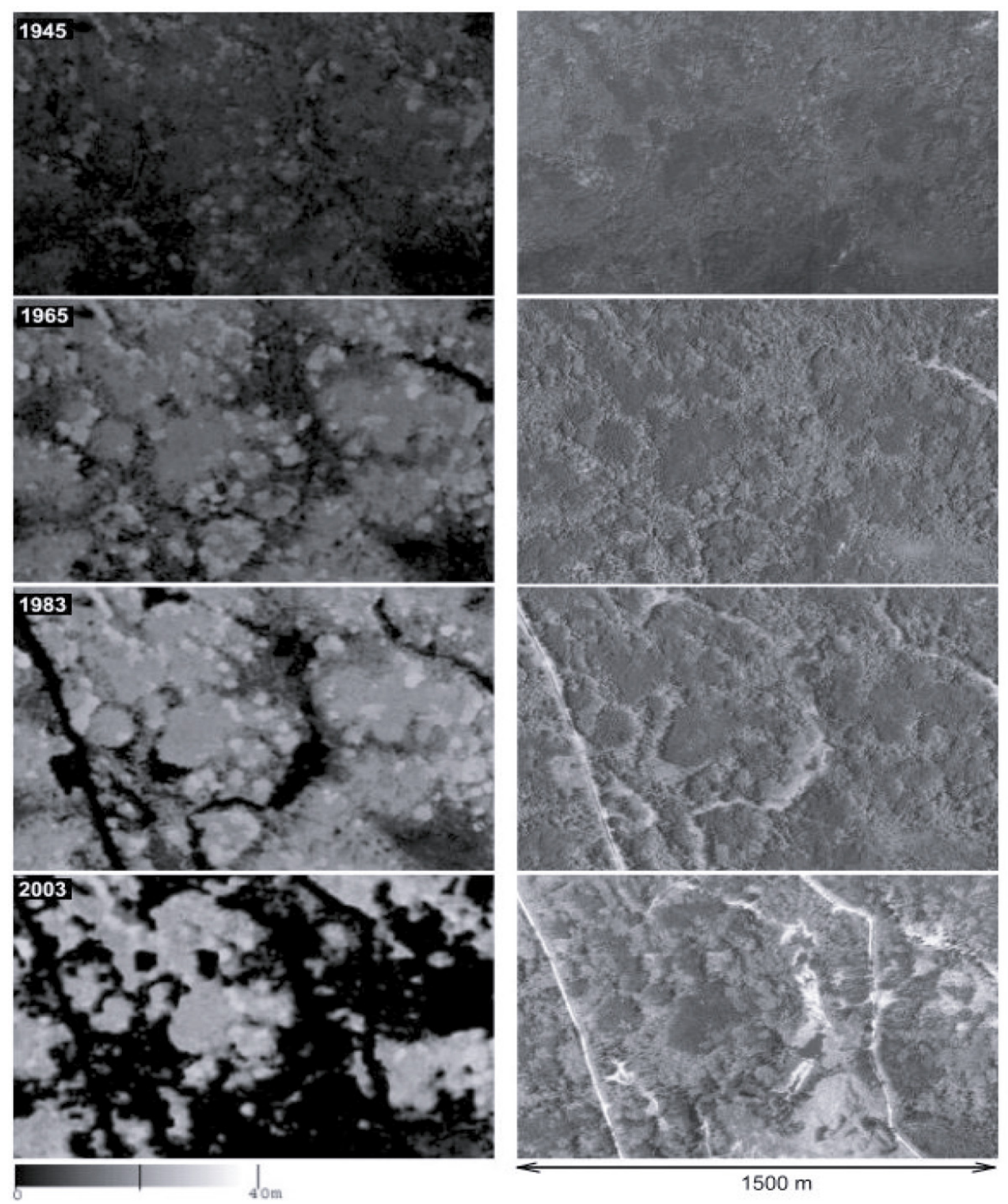
Table 1

Lidar characteristics

\begin{tabular}{ll}
\hline Lidar system & ALTM2050 \\
Power (uJ) & 200 \\
AGL Flight Altitude (m) & 1000 \\
Divergence (mrad) & 0.2 \\
Nadir footprint diameter (m) & 0.2 \\
Pulse frequency (Hz) & 50,000 \\
Max. scan angle (degree) & 15 \\
First return density (point $\left./ \mathrm{m}^{2}\right)$ & 3 \\
Last return density (point $\left./ \mathrm{m}^{2}\right)$ & 0.19 \\
\hline
\end{tabular}


Table 2

Aerial photograph characteristics

\begin{tabular}{|c|c|c|c|c|c|c|c|}
\hline $\begin{array}{l}\text { Acquisition } \\
\text { year }\end{array}$ & $\begin{array}{l}\text { Acquisition } \\
\text { date }\end{array}$ & $\begin{array}{l}\text { Camera } \\
\text { type }\end{array}$ & $\begin{array}{l}\text { Focal } \\
\text { length } \\
(\mathrm{mm})\end{array}$ & $\begin{array}{l}\text { Photo } \\
\text { scale }\end{array}$ & $\begin{array}{l}\text { Ground } \\
\text { pixel size } \\
(\mathrm{cm})\end{array}$ & $\begin{array}{l}\text { Base- } \\
\text { height } \\
\text { ratio }\end{array}$ & $\begin{array}{l}\text { Image } \\
\text { quality } \\
\text { rank* }\end{array}$ \\
\hline 2003 & 22 May & $\begin{array}{l}\text { Wild } \\
\text { RC10 }\end{array}$ & 153.51 & $1: 15000$ & 23.8 & 0.58 & 4 \\
\hline 1983 & 17 June & Wild RC8 & 152.29 & $1: 15000$ & 23.8 & 0.60 & 1 \\
\hline 1965 & 17 July & Wild RC8 & 152.29 & $1: 15840$ & 25.1 & 0.56 & 2 \\
\hline 1945 & 24 August & Fairchild & 200.9 & 1:12000 & 19.1 & 0.34 & 3 \\
\hline
\end{tabular}

* Best (1) to worst (4) image quality based on visual appraisal 
Table 3

Summary of the 2003 field reference data for individual tree heights (only for the trees later linked to photo measurements)

\begin{tabular}{lll}
\hline $\begin{array}{l}\text { Height } \\
\text { characteristics } \\
(\mathrm{m})\end{array}$ & $\begin{array}{l}\text { Conifers } \\
(\mathrm{N}=89)\end{array}$ & $\begin{array}{l}\text { Deciduous } \\
(\mathrm{N}=45)\end{array}$ \\
\hline Min & 5.6 & 9.4 \\
Mean & 22.3 & 26.4 \\
Max & 29.3 & 33.1 \\
SD & 4.96 & 4.46 \\
\hline
\end{tabular}


Table 4

RMS error of the lidar to stereo-model co-registration and average altimetric differences

(e) between lidar and photogrammetric elevations for 30 sample points on bare areas

\begin{tabular}{lllllllll}
\hline & \multicolumn{3}{l}{ Co-registration error $(\mathrm{m})$} & \multicolumn{5}{c}{ Average elevation difference in bare areas $(\mathrm{m})$} \\
\cline { 2 - 8 } & X RMS & YRMS & Z RMS & $e$ & $e \mid$ & Min & Max & SD \\
\hline 1945 & 0.78 & 0.65 & 0.85 & -0.07 & 0.48 & -0.96 & 2.29 & 0.66 \\
1965 & 0.36 & 0.25 & 1.01 & -0.35 & 0.79 & -2.58 & 1.44 & 0.94 \\
1983 & 0.63 & 0.59 & 0.49 & 0.04 & 0.3 & -0.68 & 0.84 & 0.37 \\
2003 & 0.37 & 0.25 & 0.27 & 0.03 & 0.29 & -0.77 & 0.78 & 0.38 \\
\hline
\end{tabular}


Table 5

Average bias $(\bar{\varepsilon})(\mathrm{m})$, standard deviation and corresponding quantile metrics for conifer and deciduous plots for each year

\begin{tabular}{lllllllll} 
& \multicolumn{4}{c}{ Conifers } & \multicolumn{4}{c}{ Deciduous } \\
\hline & $\bar{\varepsilon}$ & Metric & SD & RMSE & $\bar{\varepsilon}$ & Metric & SD & RMSE \\
\hline 1945 & 2.35 & $95^{\text {th }}$ & 1.23 & 1.91 & 2.46 & mean & 1.53 & 2.88 \\
1965 & 3.72 & $75^{\text {th }}$ & 0.95 & 2.97 & 2.48 & max & 1.99 & 2.50 \\
1983 & 4.00 & mean & 0.89 & 3.59 & 2.39 & $99^{\text {th }}$ & 1.30 & 2.30 \\
2003 & 3.51 & $50^{\text {th }}$ & 1.13 & 3.68 & - & - & - & - \\
\hline
\end{tabular}


Table 6

SI and dominant height coefficients for jack pine (Pothier and Savard, 1998)

\begin{tabular}{lllllll}
\hline & $b 1$ & $b 2$ & $b 3$ & $b 4$ & $b 5$ & $b 6$ \\
\hline Eq. (3) & 0.8661 & 0.9734 & 0.02840 & -0.8925 & 0.04827 & - \\
Eq. (4) & -0.03293 & 1.1486 & 1.0271 & 0.03077 & 0.9838 & 0.04563 \\
\hline
\end{tabular}


Table 7

Field versus modelled (Pothier \& Savard, 1998) mean dominant tree heights

\begin{tabular}{lllll}
\hline Min & Mean & Max & SD & RMSE \\
\hline-4.48 & 0.41 & 4.67 & 1.47 & 1.53 \\
\hline
\end{tabular}


Table 8

Field versus PCHM heights compared for 23 plots in 2003

\begin{tabular}{llllll}
\hline & $\begin{array}{l}\text { Bias } \\
(\mathrm{m})\end{array}$ & $\begin{array}{l}\text { Min } \\
(\mathrm{m})\end{array}$ & $\begin{array}{l}\text { Max } \\
(\mathrm{m})\end{array}$ & $\begin{array}{l}\text { RMSE } \\
(\mathrm{m})\end{array}$ & $\begin{array}{l}\text { Relative } \\
\text { RMSE } \\
(\%)\end{array}$ \\
\hline 1945 & 1.55 & -2.73 & 5.94 & 2.88 & 34.42 \\
1965 & 1.41 & -1.51 & 3.39 & 2.12 & 13.68 \\
1983 & 0.52 & -1.03 & 4.20 & 1.49 & 8.11 \\
2003 & 1.1 & -0.95 & 3.58 & 1.64 & 7.92 \\
\hline
\end{tabular}

